Western University

Scholarship@Western

Education Publications

Education Faculty

$8-2016$

\title{
Communication intervention for individuals with Down syndrome: Systematic review and meta- analysis
}

Nicole Neil

Western University, nneil@uwo.ca

Emily A. Jones

Queens College

Follow this and additional works at: https://ir.lib.uwo.ca/edupub

Part of the Counseling Commons, Education Commons, and the Psychology Commons

Citation of this paper:

Nicole Neil \& Emily A. Jones (2016): Communication intervention for individuals with Down syndrome: Systematic review and meta-analysis, Developmental Neurorehabilitation, DOI: 10.1080/17518423.2016.1212947 


\title{
Communication Intervention for Individuals with Down Syndrome: Systematic Review and Meta-Analysis
}

\author{
Nicole Neil a,b and Emily A. Jones b,c \\ aDepartment of Counseling, College of Education, Michigan State University, Educational \\ Psychology \& Special Education, East Lansing, MI, USA; $b$ Queens College and The Graduate

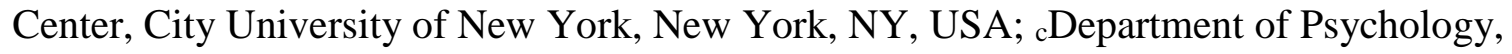 \\ Queens College, Flushing, NY, USA
}

\section{Suggested Citation:}

Nicole Neil \& Emily A. Jones (2016): Communication intervention for individuals with Down syndrome: Systematic review and meta-analysis, Developmental Neurorehabilitation, DOI: $10.1080 / 17518423.2016 .1212947$ 


\begin{abstract}
A systematic review was conducted to identify effective intervention strategies for communication in individuals with Down syndrome. We updated and extended previous reviews by examining: (1) participant characteristics; (2) study characteristics; (3) characteristics of effective interventions (e.g., strategies and intensity); (4) whether interventions are tailored to the Down syndrome behavior phenotype; and (5) the effectiveness (i.e., percentage non-overlapping data and Cohen's $d$ ) of interventions. Thirty-seven studies met inclusion criteria. The majority of studies used behaviour analytic strategies and produced moderate gains in communication targets. Few interventions were tailored to the needs of the Down syndrome behaviour phenotype. The results suggest that behaviour analytic strategies are a promising approach and future research should focus on replicating the effects of these interventions with greater methodological rigor.
\end{abstract}

Keywords: Down syndrome, communication, language, meta-analysis, intervention, intensity 
Communication Intervention for Individuals with Down Syndrome: A Systematic Review and Meta-Analysis

Individuals with Down syndrome show an early developing pattern of strengths and weaknesses $^{1}$, termed the Down syndrome behavioural phenotype, with delays and differences in speech and language development that include vocal imitation, requesting, first words, vocabulary growth, and mastery of grammar ${ }^{2,3}$. Communication impairments begin in infancy and continue into adulthood, impacting all aspects of life, including education, employment, family, and community. The extensive communication impairments mean individuals with Down syndrome may be unable to appropriately get their basic needs met, ask for help, or even engage in conversation with peers.

Given that language and communication is such a significant area of impairment there is clearly a need for intervention to address the range of communication difficulties. The examination and dissemination, however, of effective interventions for individuals with Down syndrome is limited. Over the last decade, researchers have continued to call for the development and examination of interventions to address the language and communication impairments in individuals with Down syndrome $e^{4,5}$.

Early reviews of interventions for individuals with Down syndrome suggest that early intervention programs resulted in little success or were inconclusive $\mathrm{e}^{6-8}$ in improving communication for individuals with Down syndrome. Since then, The New York State Department of Health (NYSDOH) ${ }^{9}$ conducted a review to identify effective intervention strategies for individuals with Down syndrome. They examined intervention literature for individuals with Down syndrome including single-subject and group studies of interventions. Reviewers categorized interventions by strength of evidence. Interventions having two or more 
high quality studies supporting their use were considered to have strong evidence and interventions with one moderate quality study supporting their use were considered to have limited evidence.

The New York State Department of Health Guidelines recommended that interventions for communication and language use the principles of applied behaviour analysis with intervention involving prompting and positive reinforcement, frequent and rapid delivery, with multiple opportunities to practice a skill. The recommendations for behaviour analytic interventions were, however, based on limited evidence largely from one or two moderate quality studies. From this review it was apparent behaviour analysis is a promising approach to addressing communication in individuals with Down syndrome, but that more research was needed. The recommended intensity of intervention (multiple and rapid opportunities) is also consistent with some of the early research on interventions for young children with Down syndrome $^{10}$ and supported by more recent work from Warren, Yoder and colleagues ${ }^{11-13}$.

The NYSDOH review and the reviews ${ }^{6-8}$ before it present several limitations. Reviewers only reported summary ratings for particular interventions strategies (strong to limited evidence), but did not report characteristics of individual studies. Detailed participant characteristics were not included, nor was detailed study information (e.g., design, interobserver agreement, and integrity). Further, even though there is a body of research that evaluates interventions for communication among individuals with Down syndrome, no reviews have applied meta-analytic techniques to summarize the existing research on the effectiveness of these interventions.

Since the NYSDOH review, there is also a growing body of literature describing patterns of development in individuals with Down syndrome. The unique profile of individuals with Down syndrome suggest that they may respond differently to intervention than differing 
etiologies of disability ${ }^{13}$. As a result researchers have begun to explore ways to tailor interventions to the Down syndrome behavioral phenotype ${ }^{13,14}$. Within this framework, interventions are designed to address the areas that are demonstrated weaknesses in individuals with Down syndrome while capitalizing on characteristic strengths. For example, an intervention for communication may capitalize on the relative visual processing strength by using visualvocal instruction to teach language. Delivered early, interventions targeting the phenotypic weaknesses in Down syndrome can minimize potential collateral effects. For example, interventions addressing early motivational issues in Down syndrome could lead to accessing a greater number of challenging skill building opportunities. Fidler $(2005)^{1}$ suggests that outcomes for children with Down syndrome may be improved if interventions account for characteristics within the behavioral phenotype.

In light of this emerging literature on the Down syndrome behavioral phenotype, it is important to update the NYSDOH review to identify effective intervention strategies for communication in individuals with Down syndrome. The present review is a systematic analysis of communication intervention studies for individuals with Down syndrome. We aim to update and extend previous reviews by examining: (1) participant characteristics; (2) study characteristics; (3) characteristics of effective interventions (e.g., strategies and intensity); (4) whether interventions are tailored to the Down syndrome behavior phenotype; and (5) the effectiveness (i.e., percentage non-overlapping data and effect size) of interventions.

\section{Methods}

Study Identification and Selection

Selection of studies began with a search conducted on September 30, 2014 of the PsycInfo and ERIC databases for English-language studies published between 1967 and 2014 in 
order to capture psychological and educational interventions for communication in Down syndrome. Search criteria entered included three groups of keywords. The first group of keywords were synonymous with Down syndrome including: Down* syndrome, and trisomy 21. The second group of keywords were terms used to describe language and communication and included: communication, language, and speech. The third group of key words were synonymous with intervention and included: intervention, acquisition, treatment, and teaching. The first author then used the conjunctions "OR" to combine keywords within a group and the conjunction "AND" to combine groups of keywords to search each possible combination of keywords. Based on the results of the search, articles were identified that met the inclusion criteria described next. Each identified article's reference section was then systematically analyzed for additional studies.

A study was included in the initial collection based on four criteria. First, at least one participant had a diagnosis of Down syndrome. If the article included multiple participants, only those individuals diagnosed with Down syndrome were included in the review. Second, only articles that reported the results of experimental designs (controlled trials, single-case designs) were selected; articles using non-experimental designs were excluded. Third, single-case studies were selected if baseline and treatment phases were present in the study and if repeated data points, not mean scores, were reported. Studies containing less than two baseline data points were excluded for data analysis purposes. Fourth, studies were included if treatment targeted outcomes related to speech, expressive phonology, syntax, or vocabulary. On the basis of title and abstract, the author retrieved 101 studies for detailed evaluation; an additional 24 articles were obtained from the review of reference lists. Potential studies were evaluated against the inclusion criteria, resulting in 37 studies that met inclusion criteria. The screening results from 
the first author were compared to those of a second coder (a research assistant) using the same decision criteria. Agreement was strong at $90 \%$.

Variables Coded and Reliability

Participant characteristics. The following participant information was coded: the number of participants with Down syndrome, age, gender, and level of intellectual functioning as reported in the study.

Study characteristics. The following study characteristics were coded: design, evaluation of treatment integrity data and examination of generalization and follow-up.

Intervention characteristics. The following intervention information was coded: opportunity type, intervention strategies, and intensity. Opportunity type was coded as either learner-directed, teacher-led, peer-led or a combination of two or more. Teacher-led interventions refer to those in which learning opportunities were structured, and an adult (interventionist, practitioner, or other individual) directed and initiated opportunities. Peer-led interventions were those in which learning opportunities were directed and initiated by an individual (with or without a disability) identified as a peer of the participant. Learner-directed interventions were those in which opportunities were initiated by the individual with Down syndrome.

Interventions strategies were recorded as indicated by the authors and included: Prompting, reinforcement, naturalistic language paradigm (NLP), milieu teaching, manualized reading and language intervention, and speech recasting.

The following intensity variables were coded: session duration, number of opportunities per session, sessions per week, and the total duration of intervention (in sessions) ${ }^{15}$. If intensity 
variables differed for individual participants, intensity variables were averaged across all participants with Down syndrome to yield a single value per article.

Tailoring to the Down syndrome behavior phenotype. We determined whether interventions and target behaviours were tailored to the needs of individuals with Down syndrome if the interventions had three characteristics: (1) authors identified the needs of Down syndrome in their rationale, by using the words Down syndrome in the introduction, (2) participants all had a diagnosis of Down syndrome, and (3) the target of intervention was a need identified in the Down syndrome behaviour phenotype as described by Chapman and Hesketh ${ }^{3}$. In describing the outcome variables we determined the modality (sign language, AAC devices, or vocalizations), the domain (receptive, receptive/expressive), and the verbal operant (undefined, combination of two or more, echoic, mand, tact, or intraverbal). We coded modality or form of communication as vocalization, sign language, AAC (not including signs), or combinations of two or more modalities. Target behaviours were coded as either a combination of receptive and expressive or expressive only. Expressive target behaviours were spoken responses (or adapted for use with alternative communication systems) by the participant. Receptive target behaviours were nonvocal responses to a teacher's spoken instructions. We also coded the function of the communicative behavior. One way of categorizing the function of communication is Skinner's (1957) verbal behavior model. Instructional targets are described as echoics, mands, tacts, or intraverbals. An echoic ${ }^{16}$ occurs in response to other verbal behavior, but the resulting verbal behavior matches the form of the verbal stimulus; this is often referred to as verbal imitation. For example, imitation of sounds, words, or entire phrases would be considered echoics. A mand ${ }^{16}$ is occurs when the response is under the functional control of deprivation or aversive stimulation and reinforced by a characteristic consequence. This is 
commonly referred to as a request. Examples of mands include requesting food and toys or asking for a break. A tact $^{16}$ is evoked by "a particular object or event or property of an object or event" (p. 82). This operant is commonly referred to as a label. Intraverbal refers to verbal behavior that is produced in response to other verbal behavior but is not similar in form to the preceding vocalization. A common example of an intraverbal would be answering a question such as "Where do you live?" Verbal operants could also be coded as a combination of two or more, echoic, mand, tact, or intraverbal as indicated by the authors of the study. If the authors did not indicate the verbal operant, reviewers used the descriptions of the target responses to determine the verbal operant. In some cases, not enough information about the target responses was provided to determine the verbal operant resulting in a code of undefined.

Effectiveness of interventions. Percentage of nonoverlapping data (PND) ${ }^{17}$ summarizes single-subject treatment efficacy by calculating the percentage of treatment data points that do not overlap with highest or lowest baseline data point. When more than one behaviour was targeted for a participant, the average effect size was calculated by weighting each behaviour according to the number of data points reporting on the behaviour. Within each article effect sizes were weighted according to the number of data points per participant with Down syndrome, then averaged for all participants with Down syndrome to yield a single effect size per article. All effect sizes were calculated by comparing the first baseline phase to the final treatment phase as this method accounts for the potential for researchers to withdraw their first treatment phase prior to achieving maximum effects and issues in return to baseline in reversal designs ${ }^{18}$. For alternating treatment designs, the research question for this review concerned the effect of treatment compared to baseline conditions, therefore PND was computed by comparing data in the baseline phase to data under treatment conditions during the alternating treatments phase ${ }^{18}$. 
PNDs greater than $70 \%$ were considered effective interventions, between $50 \%$ and $70 \%$, questionable, and less than $50 \%$, not effective ${ }^{17,19}$.

For group designs, reported Cohen's $d$ effect sizes were used, or effect sizes were calculated for posttest group differences from published data. Only data where the results for individuals were reported separately were included. When a study had more than one outcome variable the average of all outcome measures was calculated. Standard interpretation of Cohen's $d^{20}$ was used to consider the strength of evidence for group design studies (i.e., $<0.2=$ trivial; $0.2-0.5=$ small $; 0.5-0.8=$ moderate $;>0.8=$ strong $)$.

Interobserver Agreement. A subset of studies (32.4\%) was coded by two raters to permit the calculation of reliability estimates of variables listed in Tables 1 and 2 . The second rater held an undergraduate degree in Psychology. Interrater reliability was calculated via point-to-point agreement and was $92.9 \%$ (range $81.8 \%$ to $100 \%$ ).

Two raters also calculated PNDs for the same $32.4 \%$ of studies. For PNDs, interrater agreement was calculated using the following formula for each study: lowest PND divided by highest PND and multiplied by 100. Interrater agreement for PNDs was $100 \%$.

\section{Results}

Thirty-seven articles representing 225 participants with Down syndrome met selection criteria and were included in the analyses (Table 1). Detailed information about the articles is presented in Tables 2 and 3.

Participant Characteristics

Participant characteristics for each study are presented in Table 2. Of the 225 participants, $94(41.8 \%)$ were male, $69(30.7 \%)$ were female; gender was not reported for 62 $(27.6 \%)$. Individuals ranged in age from 0.8 to 54 years, with a mean of 10.33 years $(S D=$ 
12.07). IQ was reported for 119 participants, and the average IQ of participants was $50.84(S D=$ 19.74 , range $=18$ to 87.3 ). Of those whose IQ was reported, the majority of participants were functioning in the mild range of intellectual disability $(67.2 \%)$, followed by moderate $(21.8 \%)$, severe $(5.9 \%)$, and no intellectual disability (4.2\%).

Study Characteristics

Methodological components of studies are presented in Table 2. Studies were primarily single subject designs: $22(59.4 \%)$ multiple baseline, four $(10.8 \%)$ alternating treatment, four $(10.8 \%)$ reversal, and one $(2.7 \%)$ multiple baseline and alternating treatment design. Six studies were randomized-controlled trials (16.2\%). While multiple baseline designs are experimental, 5 studies used a multiple baselines across participants design including only 1 participant with Down syndrome and, thus, lacked experimental control for the population of interest.

Generalization data were present in $17(45.9 \%)$ of the studies. Follow up data were collected in $15(40.5 \%)$ of studies with a mean follow-up interval of 70.68 days $(S D=81.58)$. Thirty-four studies (91.8\%) collected interobserver agreement, but only $13(35.18 \%)$ studies collected a measure of intervention integrity.

Intervention Characteristics

Opportunities were teacher-led in $22(59.4 \%)$ studies, learner-directed in $12(32.4 \%)$ studies, and peer-led in 2 studies (5.4\%). One study used a combination of learner- and teacherled opportunities (2.7\%). Twenty-seven (72.9\%) studies used behaviour analytic interventions (prompting or reinforcement) and seven studies (18.9\%) used more naturalistic intervention strategies which included behaviour analytic strategies (five studies [13.5\%] used Milieu teaching, one study used mirroring and responding [2.7\%] and one [2.7 \%] study used NLP). 
Only two (5.4\%) studies used other interventions which included a manualized reading and language intervention and a morphosyntactic grammar intervention.

Table 4 presents the percentage of studies reporting intensity variables by intervention strategy and Table 5 presents a summary of the intensity characteristics of the interventions. A greater percentage of studies with teacher-led opportunities reported opportunities per session (50\%), sessions per week (86\%) and total intervention duration (91\%), than studies with childdirected opportunities (17\%,67\% and $83 \%$, respectively). A greater percentage of studies with child-directed opportunities reported session duration (100\%) than teacher-led intervention studies $(68 \%)$. On average, intervention was intense, with sessions occurring daily, lasting for 23.3 minutes, and consisting of just under 20 opportunities.

Tailoring to Down Syndrome Behaviour Phenotype

Table 3 shows the target behaviours and modality for each study. Thirty-six studies targeted expressive behaviour and one study targeted receptive behaviour in addition to expressive behaviour. Twenty-three $(62.1 \%)$ studies targeted vocalizations, four studies (10.8 $\%)$ targeted sign language, six studies (16.2\%) targeted use of an AAC device, and five studies $(13.5 \%)$ targeted a combination of two or more modalities. Verbal operant information was available for 32 studies, with nine $(24.3 \%)$ targeting mands, seven (18.9\%) targeting tacts, four $(10.8 \%)$ targeting intraverbals, one (2.7\%) targeting echoic, and $11(29.7 \%)$ targeting two or more verbal operants.

Only 12 of the 37 studies $(32.5 \%)$ met all three criteria for tailoring intervention and targets to the Down syndrome behaviour phenotype (Table 3). The majority of studies (78.3\%) targeted behaviours identified as areas of critical weakness according to the Down syndrome behaviour phenotype. Fewer studies identified Down syndrome in their rationale (17 studies, 
$45.9 \%$ ) or involved a homogenous population of individuals with Down syndrome (16 studies, $43.2 \%)$.

Effectiveness of Interventions

Means and standard deviations for each effect size grouped according to intervention strategy are shown in Table 4. On average, intervention increased communication targets by 76 $\%$, and, in $13(35.1 \%)$ of the studies, PND was at least $90 \%$. This level of PND suggests that intervention for expressive communication for individuals with Down syndrome is effective. Three group studies provided enough information for the calculation of effect size (Cohen's $d$ ): Burgoyne et al. ${ }^{21}$, Fey et al. ${ }^{11}$ and Sepúlveda, López-Villaseñor, and Garayzábal Heinze ${ }^{22}$. Effect sizes were $0.05(95 \% \mathrm{CI}=[-0.49,0.58]), 0.3(95 \% \mathrm{CI}=[-0.48,1.07])$ and $0.75(95 \% \mathrm{CI}=[-$ $0.19,1.63])$, respectively. Yoder et al. ${ }^{23}$ did not report information that permitted calculation of Cohen's $d$, but reported a moderate effect size $(g=.55)$ for post-group differences in the number of words spoken after 9 months of milieu communication training. Thus, effect sizes for group studies ranged from trivial to moderate.

\section{Discussion}

The overall appreciation of empirically supported interventions among individuals with Down syndrome has been limited by the lack of a synthesis of the available evidence. In order to address this knowledge gap, we conducted a systematic review to examine: (1) participant characteristics; (2) study characteristics; (3) characteristics of effective interventions (e.g., strategies and intensity); (4) whether interventions are tailored to the Down syndrome behavior phenotype; and (5) the effectiveness (i.e., percentage non-overlapping data and effect size) of interventions. A systematic search identified 37 studies. The results of the studies in this review 
were largely positive, and included behavior analytic strategies (prompting and reinforcement) for increasing communication, supporting the recommendations of the NYSDOH guidelines. Participant Characteristics

While the results of this review suggest the potential value of behavior-analytic strategies in increasing communication for individuals with Down syndrome, this conclusion should be considered in light of several aspects of the literature base. Published literature includes a broad age range ( 0.8 to 54 years), but for the most part, studies are targeting communication in children and youth with Down syndrome. While targeting communication early in life has the potential to minimize later deficits, there would seem to be value in evaluating whether older individuals could be taught additional communication skills to support activities of daily life. For example, as individuals with Down syndrome age, they continue to experience deficits in intelligibility ${ }^{3}$.

Many studies also included a heterogeneous group of participants, typically a small number of individuals with Down syndrome among a larger group of individuals with intellectual disability. The research in these studies, therefore, did not focus on Down syndrome, rather on the effects of a particular intervention on a particular behaviour. The result of research involving a heterogeneous group of participants is that there is no opportunity to examine intervention developed specifically for individuals with Down syndrome. Given the potential for moderating effects of etiology on intervention outcome ${ }^{13}$, there is a need to investigate interventions designed to specifically address the areas outlined in the Down syndrome behaviour phenotype ${ }^{1}$. The only way that these approaches can be validated is by designing studies that focus specifically on individuals with Down syndrome and address targets identified by the Down syndrome behaviour phenotype. 


\section{Study Characteristics}

Our inclusion criteria yielded a description of the state of the research as it currently exists, allowing commentary on weaknesses in research on interventions for communication for individuals with Down syndrome. Six studies ${ }^{26-30}$ included all four quality indicators (maintenance, generalization, integrity, and reliability) and all had high PND values (ranging from $76 \%$ to $100 \%$ ). Other studies contained an array of methodological inadequacies. General quality standards ${ }^{25}$ of intervention studies, including maintenance, generalization, and intervention integrity were inconsistently observed. Several investigations also used multiple baseline designs across participants, but only included one participant with Down syndrome. For these studies, experimental control was not demonstrated within the population included in this review, and the results of these designs are subject to the same threats to internal validity as $\mathrm{AB}$ designs. As additional quality research studies are conducted, an alternative approach to review could be to conduct a best evidence synthesis ${ }^{31}$, which would have retained only highly rigorous studies.

\section{Intervention Characteristics}

With the exception of two studies that were not behaviour analytic and several studies that used more naturalistic interventions with behaviour analytic strategies, studies in this review used behaviour analytic approaches (e.g., prompting and reinforcement). Favorable effects were seen across all behaviour analytic approaches, supporting the recommendations that behaviour analytic approaches are considered best practice in increasing communication in children with Down syndrome 9 .

Despite findings of this and previous reviews, a behavioural approach to intervention has not been widely promoted for individuals with Down syndrome. Recent reviews of speech 
impairments in individuals with Down syndrome suggest the need for interventions which target communication, but do not acknowledge the existence of behaviour-analytic interventions ${ }^{5,32,33}$. The neglect of this approach is so far-reaching in both research and practice that Buckley ${ }^{34}$ even calls for a "revival" of intensive, behavioural approaches, specifically for individuals with Down syndrome.

The New York State Department of Health Guidelines not only suggest a behaviour analytic approach to intervention but characterized the interventions as relatively intense -a large number of opportunities presented rapidly during frequent session. Overall, interventions appear to be delivered at this sort of high intensity. Interventions in this review were delivered daily, with opportunities provided once every minute, on average. Given that the majority of interventions included within this review are behaviour analytic, this is unsurprising. These interventions tend to involve multiple, teacher-led opportunities presented in close proximity with specific prompting procedures, high rates of reinforcement, and error correction procedures. In order to account for how variations in intervention intensity impact outcomes, future studies need to report intensity characteristics in greater detail. Many studies report the total number sessions (total intervention duration) delivered to participants and the duration of those sessions, but fewer report how frequently sessions occur or the number of opportunities provided to participants within sessions. Less than a third of the studies report all of these characteristics. It is necessary for researchers to report multiple aspects of intensity so that future analyses can begin to consider dose-response relationships in communication intervention.

Some differences in reporting intensity characteristics may be a function of the different intervention strategies. Different approaches to treatment emphasize intensity differently. For example, interventions with child-directed opportunities may not report, or even have knowledge 
of the number of opportunities being presented. Thus, what exactly constitutes a dose for these interventions is unclear. Researchers need to consider how interventions in their field could be examined to permit identification of the active ingredients in order to recommend an optimal dose of those interventions. Researchers and clinicians require this information to deliver the active ingredients in the best possible form.

Tailoring to Down Syndrome Behaviour Phenotype

In this review, the studies targeted areas of critical weaknesses, but did not consider the unique contributions of Down syndrome in their rationale or examine the effects of intervention specifically for a population of individuals with Down syndrome. Although many studies targeted areas of critical weakness in young children, this does not indicate that researchers considered the unique needs of individuals with Down syndrome given the criteria used for categorizing areas for young children was quite broad. Interventions were considered to target an area of critical weakness if they targeted expressive vocabulary development in individuals younger than 12. Given that the focus of this review was on studies of expressive communication, any interventions delivered to young children met this criteria. Few studies focused on the more idiosyncratic needs of individuals with Down syndrome, such as grammar development in older childhood and nonverbal requesting in infancy.

Although twelve studies met criteria for tailoring to the Down syndrome behavioral phenotype, they did not show effect sizes larger than interventions which did not. Much of the descriptive literature on Down syndrome suggests that individuals with Down syndrome would benefit from interventions that are tailored to their critical areas of strengths and weaknesses ${ }^{1,24}$ and these ideas need empirical support. For example, Bauer and Jones (2014) created an intervention to teach early requesting skills using the behavioral phenotype to inform 
intervention characteristics. The authors targeted a skill which was significantly delayed in children with Down syndrome, provided high rates of social reinforcement (building on the social strength characteristic of individuals with Down syndrome), and taught the skill by breaking it down in to smaller components. In order to deconstruct the requesting skill, intervention progressed through a sequence of requesting situations building from more social (involving attaining caregiver interaction) to more instrumental (involving attaining an object). This sequence was informed by Fidler et al.'s (2005) finding that instrumental requests are more significantly impaired than social requests in infants with Down syndrome. As a result, the intervention improved requesting for three children with Down syndrome. Effectiveness of Interventions

Our effectiveness calculations showed that most studies resulted in gains in communication for most participants. Prompting and reinforcement, naturalistic language paradigm and milieu teaching all demonstrated PNDs consistent with effective interventions (>70\%). Despite differing names, naturalistic language paradigm and milieu teaching also involve behavior analytic techniques (prompting and reinforcement) within the intervention. They differ from highly structured approaches (e.g., discrete trial teaching) by teaching skills in a loosely structured format, where learning trials are initiated by the learner, and by teaching in environments which resemble the typical daily activities that a young child may encounter. If we consider these approaches under the umbrella of behavior analysis, it is clear that behavioranalytic strategies are effective interventions for communication among individuals with Down syndrome.

Close inspection of the data reported in Table 2, indicates that about five of the studies have PND values which rank in the ineffective range according to the criteria by Scruggs et al. 
$(1987)^{35}$. One of these studies used mirroring and responding by peers, where typically developing siblings were taught to imitate what their siblings with Down syndrome said, and respond to vocalizations. The low PND suggests this strategy is less effective than interventions which include prompting and reinforcement.

The other three studies with low PNDs did, however, include prompting and reinforcement, raising the possibility of individual difference variables being responsible for these differential outcomes. In these three studies the individuals with Down syndrome showed severe and profound intellectual disability ${ }^{36,37}$, limited vocalizations ${ }^{38}$, and dual diagnosis with autism spectrum disorders ${ }^{39}$. Individuals with Down syndrome present with heterogeneous deficits and it is likely that these individual differences are also reflected in the included studies. These differences also may have contributed to the range of communication outcomes observed across included studies.

Percentage of non-overlapping data is a commonly used method and one of the most accepted methods to conduct meta-analyses with single-subject research. Although meta-analytic techniques provide unbiased evaluation of the data contained within the studies, the techniques used in this review have limitations. PND provides a metric of effectiveness of intervention, but interpretation of the magnitude of effect based solely on the mean percentage non-overlap is not recommended as PND is not considered a true effect size ${ }^{40}$. Readers should also note the variability in percentage of non-overlapping data for the studies included in this review. Since we did not include "grey" literature, it is possible that the effect sizes in this study are overestimates of the true effect of intervention. Finally, despite including several randomized controlled trials in this review, only three reported enough data to permit the calculation of an effect size. 


\section{Recommendations for Research and Practice}

From this review, we can make a number of recommendations for researchers and practitioners considering interventions for communication among individuals with Down syndrome. First, we need studies that focus on the specific needs of individuals with Down syndrome, tailoring intervention to the critical areas of weakness. This also means designing studies that include only participants with Down syndrome. With the growing literature on the behavioral characteristics of individuals with Down syndrome, studies should be designed with the Down syndrome behavioural phenotype in mind. We also need to produce these studies with methodological rigor. Researchers need to monitor the degree to which therapists adhere to treatment protocols as well as maintenance and generalization outcomes. A wide adoption of these standards may establish a clearer picture of the promising effects of behaviour analytic intervention and may constitute the basis for decision-making in public health and social policies relating to Down syndrome and developmental disabilities.

Researchers and practitioners should consider adopting behaviour analytic treatment strategies. This review suggests that there is evidence that behaviour analytic techniques improve communication and language outcomes among individuals with Down syndrome and that behaviour analytic interventions should be recommended for individuals with Down syndrome over other approaches without support. That is not to say that other approaches to intervention are not without merit, merely that we should use them with caution until they have been evaluated by objective methods.

There are many reasons why alternative approaches to intervention have not been sufficiently evaluated. Over many years, practitioners have used commonly accepted interventions for increasing communication in individuals with Down syndrome. Because these 
methods are so well established in practice, it is difficult to evaluate them by objective methods. Families and practitioners may be reluctant to participate in trials of already "established" interventions. Other problems in evaluating effectiveness comes from the diversity of individuals with Down syndrome; age, degree of impairment, and associated medical diagnoses are all variables that need to be considered. Evaluations of these interventions need to account for differences other than the just the intervention being investigated. There is a need for researchers with both funding and technical skills to evaluate interventions for communication in Down syndrome in order to prevent practitioners and families from continuing to use interventions without adequate support for their usefulness.

Last, more research is needed to determine the moderating effects of intervention intensity. In order to determine how participant characteristics and other intervention characteristics interact with intervention intensity, there need to be studies with clear descriptions of intensity characteristics. Reporting intensity characteristics allows other researchers to replicate, and allows practitioners to understand the necessity of these characteristics in producing meaningful outcomes for individuals with Down syndrome. This in turn can help inform policies about which interventions and how much of them should be delivered to families of individuals with Down syndrome. 


\section{Acknowledgements}

Thank you to Antesh Sharma for her assistance coding articles. 


\section{Declaration of Interest}

The authors report no declarations of interest. 


\section{References}

1. Fidler DJ. The emerging Down syndrome behavioral phenotype in early childhood. Infants Young Child. 2005;18(2):86-103. doi:10.1097/00001163-200504000-00003.

2. Buckley S. Developing the speech and language skills of teenagers with Down's syndrome. Downs Syndr Res Pr. 1993;1(2):63-71. doi:10.3104/reports.12.

3. Chapman RS, Hesketh LJ. Language, cognition, and short-term memory in individuals with Down syndrome. Downs Syndr Res Pract. 2001;7(1):1-7. doi:10.3104/reviews.108.

4. Abbeduto L, Warren SF, Conners FA. Language development in Down syndrome: From the prelinguistic period to the acquisition of literacy. Ment Retard Dev Dsabilities. 2007;13:247-261. doi:10.1002/mrdd.20158.

5. Roberts JE, Price J, Malkin C. Language and Communication in Down syndrome. Ment Retard Dev Disabil Res Rev. 2007;13(2):26-35. doi:10.1002/mrdd.20136.

6. Nilholm C. Early intervention with children with Down syndrome - Past and future issues. Down Syndr Res Pract. 1996;4(2):51-58. doi:10.3104/reviews.62.

7. Gibson D, Harris A. Aggregated early intervention effects for Down's syndrome persons: patterning and longevity of benefits. J Ment Defic Res. 1988;32 ( Pt 1):1-17. doi:10.1111/j.1365-2788.1988.tb01384.x.

8. Gunn P, Berry P. Education of infants with down syndrome. Eur J Psychol Educ. 1989;4(2):235-246. doi:10.1007/BF03172606.

9. New York State Department of Health (NSYDOH). Report of the Recommendations: Down Syndrome Assessment and Intervention for Young Children (age 0 - 3 Years).; 2006.

10. Hanson MJ. Teaching the Infant with Down Syndrome: A Guide for Parents and Professonals (2nd Ed.). Austin, TX: Pro-ed; 1987.

11. Fey ME, Warren SF, Brady N, et al. Early effects of responsivity education/prelinguistic milieu teaching for children with developmental delays and their parents. J Speech Lang Hear Res. 2006;49(3):526-547. doi:10.1044/1092-4388(2006/039).

12. Yoder PJ, Warren SF. Effects of prelinguistic milieu teaching and parent responsivity education on dyads involving children with intellectual disabilities. J Speech Lang Hear Res. 2002;45(6):1158-1174. doi:10.1044/1092-4388(2002/094).

13. Yoder P, Woynaroski T, Fey M, Warren S. Effects of dose frequency of early communication intervention in young children with and without down syndrome. Am J Intellect Dev Disabil. 2014;119(1):17-32. doi:10.1352/1944-7558-119.1.17.

14. Bauer SM, Jones E a. Requesting and verbal imitation intervention for infants with Down syndrome: Generalization, intelligibility, and problem solving. J Dev Phys Disabil. 2014;27(1):37-66. doi:10.1007/s 10882-014-9400-6.

15. Warren SF, Fey ME, Yoder PJ. Differential treatment intensity research: A missing link to creating optimally effective communication interventions. Ment Retard Dev Disabil Res Rev. 2007;13:70-77. doi:10.1002/mrdd.

16. Skinner BF. Verbal Behavior. In: Verbal Behavior.; 1957. 
17. Scruggs TE, Mastropieri MA, Casto G. Methodology and validation. Remedial Spec Educ. 1980;8(1980):24-33.

18. Allison DB, Gorman BS. Calculating effect sizes for meta-analysis: The case of the single case*. Behav Res Ther. 1993;31(6):621-631. doi:10.1016/0005-7967(93)90115-B.

19. Scruggs TE, Mastropieri MA. How to Summarize Single-Participant Research: Ideas and Applications. Exceptionality. 2001;9(4):227-244. doi:10.1207/ S15327035EX0904_5.

20. Cohen J. A power primer. Quant Methods Psychol. 1992;112(1):155-159. doi:http://dx.doi.org/10.1037/0033-2909.112.1.155.

21. Burgoyne K, Duff FJ, Clarke PJ, Buckley S, Snowling MJ, Hulme C. Efficacy of a reading and language intervention for children with Down syndrome: A randomized controlled trial. J Child Psychol Psychiatry Allied Discip. 2012;53(10):1044-1053. doi:10.1111/j.1469-7610.2012.02557.x.

22. Sepúlveda EM, López-Villaseñor ML, Heinze EG. Can individuals with Down syndrome improve their grammar? Int J Lang Commun Disord. 2013;48(3):343-349. doi:10.1111/1460-6984.12002.

23. Yoder PJ, Woynaroski T. How to study the influence of intensity of treatment on generalized skill and knowledge acquisition in students with disabilities. J Behav Educ. 2014;24(1):152-166. doi:10.1007/s10864-014-9216-6.

24. Hodapp RM, Fidler DJ. Special education and genetics: Connections for the 21st century. J Spec Educ. 1999;33(3):130-137. doi:10.1177/002246699903300301.

25. Reichow B, Volkmar FR, Cicchetti D V. Development of the evaluative method for evaluating and determining evidence-based practices in autism. J Autism Dev Disord. 2008;38(7):1311-1319. doi:10.1007/s10803-007-0517-7.

26. Tekin-Iftar E. Effectiveness of peer delivered simultaneous prompting on teaching community signs to students with developmental disabilities . Educ Train Dev Disabil . 2003;38 (1 ):77-94.

27. Hemmeter ML, Meyer S, Ault MJ, Collins B. The effects of teacher-implemented language instruction within free time activities. Educ Train Ment Retard Dev Disabil. 1996;31(3):203-212. http://www.jstor.org/stable/23879447.

28. Feeley KM, Jones E a., Blackburn C, Bauer S. Advancing imitation and requesting skills in toddlers with Down syndrome. Res Dev Disabil. 2011;32(6):2415-2430. doi:10.1016/j.ridd.2011.07.018.

29. Bauer SM, Jones EA, Feeley KM. Teaching responses to questions to young children with Down syndrome. Behav Interv. 2014;29:36-49. doi:10.1002/bin.

30. Bauer SM, Jones EA. A behavior analytic approach to exploratory motor behavior. Infants Young Child. 2014;27(2):162-173. doi:10.1097/IYC.0000000000000004.

31. Slavin RE. Ability grouping and student achievement in elementary schools: A bestevidence synthesis. Rev Educ Res. 1987;57(3):293-336. doi:10.3102/00346543057003293.

32. Kent RD, Vorperian HK. Speech impairment in Down syndrome: a review. J Speech Lang Hear Res. 2013;56(1):178-210. doi:10.1044/1092-4388(2012/12-0148). 
33. Martin GE, Klusek J, Estigarribia B, Roberts JE. Language characteristics of individuals with Down syndrome. Top Lang Disord. 2009;29(2):112-132. doi:10.1097/TLD.0b013e3181a71fe1.

34. Buckley S. The power of behavioural approaches - we need a revival. Downs Syndr Res Pract. 2008;12(2):103-104. doi:10.3104/updates/2038.

35. Scruggs TE, Mastropieri MA, Casto G. The quantitative synthesis of single-subject research: Methodology and validation. Remedial Spec Educ. 1987;8:24-33. doi:10.1177/074193258700800206.

36. Gutierrez A, Vollmer TR, Samaha AL. Developing and assessing stimulus control based on establishing operations during mand training using representative objects. Behav Interv. 2010;25(2):169-182. doi:10.1002/bin.302.

37. Tirapelle L, Cipani E. Developing functional requesting: acquisition, durability, and generalization of effects. Except Child. 1991;58(3):260-269.

38. Iacono T, Duncum JE. Comparison of sign alone and in combination with an electronic communication device in early language intervention: Case study. Augment Altern Commun. 1995;11(4):249-259. doi:10.1080/07434619512331277389.

39. Valentino AL, Shillingsburg MA, Call NA. Comparing the effects of echoic prompts and echoic prompts plus modeled prompts on intraverbal behavior. J Appl Behav Anal. 2012;45(2):431-435. doi:10.1901/jaba.2012.45-431.

40. Banda DR, Therrien WJ. A teacher's guide to meta-analysis. Teach Except Child. 2008;42(2):66-71. doi:10.1177/004005990804100208.

41. Binger C, Light J. The effect of aided AAC modeling on the expression of multi-symbol messages by preschoolers who use AAC. Augment Altern Commun. 2007;23(1):30-43. doi:10.1080/07434610600807470.

42. Camarata S, Yoder P, Camarata M. Simultaneous treatment of grammatical and speechcomprehensibility deficits in children with Down syndrome. Downs Syndr Res Pract. 2006;11(1):9-17. doi:10.3104/reports.314.

43. Chambers M, Rehfeldt RA. Assessing the acquisition and generalization of two mand forms with adults with severe developmental disabilities. Res Dev Disabil. 2003;24(4):265-280. doi:10.1016/S0891-4222(03)00042-8.

44. Cottrell AW, Montague J, Farb J, Throne JM. An operant procedure for improving vocabulary definition performances in developmentally delayed children. J Speech Hear Disord. 1980;45(1):90-102.

45. Drash PW, Raver SA, Murrin MR, Tudor RM. Three procedures for increasing vocal response to therapist prompt in infants and children with Down syndrome. Am J Ment Retard. 1989;94(1):64-73.

46. Duker PC, Michielsen HM. Cross-setting generalization of manual signs to verbal instructions with severely retarded children. Appl Res Ment Retard. 1983;4(1):29-40. doi:10.1016/S0270-3092(83)80016-2.

47. Feeley K, Jones E. Teaching spontaneous responses to a young child with Down syndrome. Downs Syndr Res Pract. 2008;12(2):148-152. doi:10.3104/case-studies.2007. 
48. Haring TG, Roger B, Lee M, Breen C, Gaylord-Ross R. Teaching social language to moderately handicapped students. J Appl Behav Anal. 1986;19(2):159-171. doi:10.1901/jaba.1986.19-159.

49. Heller KW, Allgood MH, Ware S, Arnold SE, Castelle MD. Initiating requests during community-based vocational training by students with mental retardation and sensory impairments. Res Dev Disabil. 1996;17(3):173-184. doi:10.1016/0891-4222(95)00040-2.

50. Kouri T. Effects of simultaneous communication in a child-directed treatment approach with preschoolers with severe disabilities. Augment Altern Commun. 1988;4(4):222-232. doi:10.1080/07434618812331274827.

51. Kroeger KA, Nelson WM. A language programme to increase the verbal production of a child dually diagnosed with Down syndrome and autism. J Intellect Disabil Res. 2006;50(2):101-108. doi:10.1111/j.1365-2788.2005.00734.X.

52. LeBlanc LA, Geiger KB, Sautter RA, Sidener TM. Using the Natural Language Paradigm (NLP) to increase vocalizations of older adults with cognitive impairments. Res Dev Disabil. 2007;28(4):437-444. doi:10.1016/j.ridd.2006.06.004.

53. Mirenda P, Dattilo J. Instructional techniques in alternative communication for students with severe intellectual handicaps. Augment Altern Commun. 1987;3(3):143-152. doi:10.1080/07434618712331274429.

54. Poulson CL. Operant conditioning of vocalization rate of infants with Down syndrome. Am J Ment Retard. 1988;93(1):57-63.

55. Remington B, Clarke S. Simultaneous communication and speech comprehension. Part I: comparison of two methods of teaching expressive signing and speech comprehension skills. Augment Altern Commun. 1993;9(1):36-48. doi:10.1080/07434619312331276391.

56. Remington B, Clarke S. Simultaneous communication and speech comprehension. Part II: Comparison of two methods of overcoming selective attention during expressive sign training. Augment Altern Commun. 1993;9(1):49-60. doi:doi: 10.1080/07434619312331276401.

57. Rosales R, Rehfeldt RA. Contriving transitive conditioned establishing operations to establish derived manding skills in adults with severe developmental disabilities. $J$ Appl Behav Anal. 2007;40(1):105-121. doi:10.1901/jaba.2007.117-05.

58. Sigafoos J, Doss S, Reichle J. Developing mand and tact repertoires in persons with severe developmental disabilities using graphic symbols. Res Dev Disabil. 1989;10(2):183-200. doi:10.1016/0891-4222(89)90006-1.

59. Sigafoos J, Green V a, Payne D, Son S-H, O’Reilly M, Lancioni GE. A comparison of picture exchange and speech-generating devices: acquisition, preference, and effects on social interaction. Augment Altern Commun. 2009;25(2):99-109. doi:10.1080/07434610902739959.

60. Thompson RH, Cotnoir-Bichelman NM, McKerchar PM, Tate TL, Dancho K a. Enhancing early communication through infant sign training. J Appl Behav Anal. 2007;40(1):15-23. doi:10.1901/jaba.2007.23-06.

61. Trent JA, Kaiser AP, Wolery M. The use of responsive interaction strategies by siblings. Topics Early Child Spec Educ. 2005;25(2):107-118. 
doi:10.1177/02711214050250020101.

62. Warren SF, Yoder PJ, Gazdag GE, Kim K, Jones HA. Facilitating prelinguistic communication skills in young children with developmental delay. J Speech Hear Res. 1993;36(1):83-97.

63. Wright CA, Kaiser AP, Reikowsky DI, Roberts MY. Effects of a naturalistic sign intervention on expressive language of toddlers with down syndrome. J Speech Lang Hear Res. 2013;56(3):994-1008. doi:10.1044/1092-4388(2012/12-0060)994. 
Table 1

Description of articles $(N=37)$.

\begin{tabular}{|c|c|c|}
\hline \multirow[b]{2}{*}{ Characteristic } & \multirow[t]{2}{*}{$n$} & \multirow[t]{2}{*}{$\begin{array}{l}\text { Percentage } \\
\text { of Studies }\end{array}$} \\
\hline & & \\
\hline \multicolumn{3}{|l|}{ Journal Title } \\
\hline Augmentative and Alternative Communication & 7 & $18.9 \%$ \\
\hline Research in Developmental Disabilities & 5 & $13.5 \%$ \\
\hline Journal of Applied Behaviour Analysis & 4 & $10.8 \%$ \\
\hline Journal of Speech, Language, and Hearing Research & 3 & $8.1 \%$ \\
\hline American Journal on Mental Retardation & 2 & $5.4 \%$ \\
\hline Behavioural Interventions & 2 & $5.4 \%$ \\
\hline Down Syndrome Research and Practice & 2 & $5.4 \%$ \\
\hline Journal of Speech and Hearing Disorders & 2 & $5.4 \%$ \\
\hline American Journal on Intellectual and Developmental Disabilities & 1 & $2.7 \%$ \\
\hline Applied Research in Mental Retardation & 1 & $2.7 \%$ \\
\hline Education and Training in Developmental Disabilities & 1 & $2.7 \%$ \\
\hline Education and Training in Mental Retardation and Developmental Disabilities & 1 & $2.7 \%$ \\
\hline Exceptional Children & 1 & $2.7 \%$ \\
\hline International Journal of Language and Communication Disorders & 1 & $2.7 \%$ \\
\hline Journal of Developmental and Physical Disabilities & 1 & $2.7 \%$ \\
\hline Journal of Intellectual Disability Research & 1 & $2.7 \%$ \\
\hline Topics in Early Childhood Special Education & 1 & $2.7 \%$ \\
\hline \multicolumn{3}{|l|}{ Year Published } \\
\hline $1980-1989$ & 8 & $21.6 \%$ \\
\hline $1990-1999$ & 7 & $18.9 \%$ \\
\hline $2000-2009$ & 13 & $35.1 \%$ \\
\hline $2009-2014$ & 9 & $24.3 \%$ \\
\hline \multicolumn{3}{|l|}{ Number of Participants $(\mathrm{M}=6.86, \mathrm{SD}=14.28)$} \\
\hline 1 & 20 & $54.1 \%$ \\
\hline 2 & 5 & $13.5 \%$ \\
\hline 3 & 2 & $5.4 \%$ \\
\hline 4 & 2 & $5.4 \%$ \\
\hline 5 & 1 & $2.7 \%$ \\
\hline$>6$ & 7 & $18.9 \%$ \\
\hline Total $N$ & 37 & $100.0 \%$ \\
\hline
\end{tabular}

Note: The symbol $n$ denotes a number of articles. 
Table 2

Participant and study characteristics of intervention studies targeting communication for individuals with Down syndrome.

\begin{tabular}{|c|c|c|c|c|c|c|c|c|c|}
\hline \multicolumn{5}{|c|}{ Participant Characteristics } & \multicolumn{5}{|c|}{ Study Characteristics } \\
\hline Authors & $\mathrm{n}$ & $\begin{array}{l}\text { n with } \\
\text { DS }\end{array}$ & $\begin{array}{l}\text { Mean } \\
\text { Age }\end{array}$ & $\begin{array}{c}\# \\
\text { Male }\end{array}$ & Design & $\begin{array}{l}\text { Maintenanc } \\
\mathrm{e}\end{array}$ & $\begin{array}{c}\mathrm{Ge} \\
\mathrm{n}\end{array}$ & $\begin{array}{c}\text { Integrit } \\
\mathrm{y}\end{array}$ & $\begin{array}{c}\mathrm{IO} \\
\mathrm{A}\end{array}$ \\
\hline Bauer \& Jones (2014) ${ }^{14}$ & 5 & 5 & 0.85 & 4 & MB Across Behaviours & $\mathrm{Y}$ & $\mathrm{Y}$ & $\mathrm{Y}$ & $\bar{Y}$ \\
\hline Bauer et al. $(2014)^{29}$ & 2 & 2 & 2.5 & 2 & MB Across Behaviours & Y & $\mathrm{Y}$ & $\mathrm{Y}$ & $\mathrm{Y}$ \\
\hline Binger \& Light $(2007)^{41}$ & 5 & 1 & 4.5 & 0 & MB Across Participants & $\mathrm{Y}$ & $\mathrm{Y}$ & $\mathrm{N}$ & $\mathrm{Y}$ \\
\hline Burgoyne et al. $(2012)^{21}$ & $\begin{array}{l}5 \\
7\end{array}$ & 57 & 6.6 & 28 & $\mathrm{RCT}$ & $\mathrm{N}$ & $\mathrm{Y}$ & $\mathrm{N}$ & $\mathrm{N}$ \\
\hline Camarata et al. $(2006)^{42}$ & 6 & 6 & 5.7 & 3 & MB Across Participants & $\mathrm{N}$ & $\mathrm{N}$ & $\mathrm{N}$ & $\mathrm{Y}$ \\
\hline Chambers \& Rehfeldt $(2003)^{43}$ & 4 & 1 & 40 & 0 & AT & $\mathrm{N}$ & $\mathrm{Y}$ & $\mathrm{N}$ & $\mathrm{Y}$ \\
\hline Cottrell et al. $(1980)^{44}$ & 1 & 1 & 6.6 & 0 & MB Across Behaviours & Y & $\mathrm{Y}$ & $\mathrm{N}$ & $\mathrm{Y}$ \\
\hline Drash et al. $(1989)^{45}$ & $\begin{array}{l}1 \\
5\end{array}$ & 15 & 2.2 & 9 & $\mathrm{RCT}$ & $\mathrm{N}$ & $\mathrm{N}$ & $\mathrm{N}$ & $\mathrm{Y}$ \\
\hline Duker \& Michielsen $(1983)^{46}$ & 3 & 1 & 12 & 0 & MB Across Behaviours & $\mathrm{N}$ & $\mathrm{Y}$ & $\mathrm{N}$ & $\mathrm{Y}$ \\
\hline Feeley et al. $(2011)^{28}$ & 4 & 4 & 1.7 & 1 & MB Across Behaviours & $\mathrm{Y}$ & $\mathrm{Y}$ & $\mathrm{Y}$ & $\mathrm{Y}$ \\
\hline Feeley \& Jones $(2008)^{47}$ & 1 & 1 & 3.8 & 0 & MB Across Behaviours & $\mathrm{Y}$ & $\mathrm{Y}$ & $\mathrm{Y}$ & $\mathrm{Y}$ \\
\hline Fey et al. $(2006)^{11}$ & $\begin{array}{l}5 \\
1\end{array}$ & 26 & 4.2 & $*$ & $\mathrm{RCT}$ & $\mathrm{N}$ & $\mathrm{N}$ & $\mathrm{N}$ & $\mathrm{Y}$ \\
\hline Gutierrez et al. $(2010)^{36}$ & 2 & 1 & 16 & 1 & MB Across Behaviours and AT & $\mathrm{N}$ & $\mathrm{N}$ & $\mathrm{N}$ & $\mathrm{Y}$ \\
\hline Haring et al. $(1986)^{48}$ & 3 & 1 & 10 & 0 & MB Across Behaviours and Participants & $\mathrm{Y}$ & $\mathrm{Y}$ & $\mathrm{N}$ & $\mathrm{Y}$ \\
\hline Heller et al. $(1996)^{49}$ & 4 & 1 & 18.3 & - & MB Across Participants & $\mathrm{N}$ & $\mathrm{Y}$ & $\mathrm{N}$ & $\mathrm{Y}$ \\
\hline Hemmeter et al. $(1996)^{27}$ & 4 & 2 & 6.6 & 2 & MB Across Participants & $\mathrm{Y}$ & $\mathrm{Y}$ & $\mathrm{Y}$ & $\mathrm{Y}$ \\
\hline Iacono \& Duncum $(1995)^{38}$ & 1 & 1 & 2.7 & 0 & AT & Y & $\mathrm{N}$ & $\mathrm{Y}$ & $\mathrm{Y}$ \\
\hline Kouri $(1988)^{50}$ & 5 & 1 & 2.8 & 0 & Reversal & $\mathrm{N}$ & $\mathrm{N}$ & $\mathrm{N}$ & $\mathrm{Y}$ \\
\hline Kroeger \& Nelson $(2006)^{51}$ & 1 & 1 & 9 & 1 & Reversal & $\mathrm{Y}$ & $\mathrm{N}$ & $\mathrm{N}$ & $\mathrm{Y}$ \\
\hline LeBlanc et al. $(2007)^{52}$ & 3 & 1 & 54 & 0 & MB Across Participants & $\mathrm{N}$ & $\mathrm{N}$ & $\mathrm{Y}$ & $\mathrm{Y}$ \\
\hline Mirenda \& Dattilo $(1987)^{53}$ & 3 & 1 & 11.2 & 0 & MB Across Participants & $\mathrm{N}$ & $\mathrm{N}$ & $\mathrm{N}$ & Y \\
\hline Poulson $(1988)^{54}$ & 3 & 3 & 0.44 & 1 & Reversal & $\mathrm{N}$ & $\mathrm{N}$ & $\mathrm{Y}$ & $\mathrm{Y}$ \\
\hline Remington \& Clarke (1993a) ${ }^{55}$ & 5 & 3 & 8.8 & 1 & MB Across Behaviours & $\mathrm{N}$ & $\mathrm{N}$ & $\mathrm{N}$ & $\mathrm{Y}$ \\
\hline
\end{tabular}


Remington \& Clarke $(1993 b)^{56}$

Rosales \& Rehfeldt (2007) ${ }^{57}$

Sepúlveda et al. (2013) ${ }^{22}$

Sigafoos et al. (1989) $)^{58}$

Sigafoos et al. (2009) $)^{59}$

Tekin-Iftar $(2003)^{26}$

Thompson et al. (2007) ${ }^{60}$

Tirapelle, \& Cipani (1991) $)^{37}$

Trent et al. (2005) ${ }^{61}$

Valentino et al. (2012) $)^{39}$

Warren et al. (1993) ${ }^{62}$

Wright et al. (2013) ${ }^{63}$

Yoder \& Warren (2002) ${ }^{12}$

Yoder et al. $(2014)^{13}$
6

2

10.9

1 MB Across Behaviours

$1 \quad 34$

20

10.7

0 MB Across Participants

11 RCT

361 MB Across Behaviours

$15 \quad 0 \quad$ AT

$11.1 \quad 1$ MB Across Behaviours

$0.8 \quad 0 \quad$ Reversal

61 MB Across Participants

60 MB Across Participants

$13.9 \quad 0 \quad$ AT

1.8

2.1

1.8

2 MB Across Behaviours and Participants

2 MB Across Participants

22 RCT

35

1.8

- RCT

$\begin{array}{cccc}\text { N } & \text { N } & \text { N } & \text { Y } \\ \text { Y } & \text { N } & \text { N } & \text { Y } \\ \text { N } & \text { N } & \text { N } & \text { N } \\ & & & \\ \text { N } & \text { N } & \text { Y } & \text { Y } \\ \text { N } & \text { N } & \text { N } & \text { Y } \\ \text { Y } & \text { Y } & \text { Y } & \text { Y } \\ \text { N } & \text { Y } & \text { N } & \text { Y } \\ \text { Y } & \text { Y } & \text { N } & \text { Y } \\ \text { Y } & \text { N } & \text { Y } & \text { Y } \\ \text { N } & \text { N } & \text { N } & \text { Y } \\ \text { N } & \text { Y } & \text { N } & \text { Y } \\ \text { N } & \text { Y } & \text { Y } & \text { Y } \\ \text { N } & \text { N } & \text { N } & \text { Y } \\ & & & \\ \text { Y } & \text { N } & \text { Y } & \text { Y }\end{array}$

“_“ = not reported, Gen =generalization, MB = Multiple Baseline, AT = Alternating Treatments 
Table 3

Tailoring to phenotype, intervention characteristics and effectiveness of studies targeting communication intervention in individuals with Down syndrome.

\begin{tabular}{|c|c|c|c|c|c|c|c|c|c|}
\hline \multirow[b]{2}{*}{ Authors } & \multirow{2}{*}{\multicolumn{2}{|c|}{$\begin{array}{c}\text { Tailored to Phenotype } \\
\text { Target Behaviour: Modality, } \\
\text { Expressive/receptive, Verbal } \\
\text { Operant }\end{array}$}} & \multicolumn{2}{|c|}{ Intervention Characteristics } & \multicolumn{4}{|c|}{ Intensity Characteristics } & \multirow[b]{2}{*}{ PND } \\
\hline & & & Strategies & $\begin{array}{l}\text { Opportunity } \\
\text { Type }\end{array}$ & $\begin{array}{l}\text { Opportunities } \\
\text { /Session }\end{array}$ & $\begin{array}{l}\text { Sessions } \\
\text { /Week }\end{array}$ & $\begin{array}{l}\text { Session } \\
\text { Duration } \\
(\min )\end{array}$ & $\begin{array}{l}\text { Duration of } \\
\text { Intervention } \\
\text { (sessions) }\end{array}$ & \\
\hline Bauer \& Jones $(2014)^{6}$ & $\mathrm{Y}$ & Voc., exp., echoic and mands & $\begin{array}{l}\text { Prompting, } \\
\text { Reinforcement }\end{array}$ & Teacher-led & 10 & 2.5 & - & 27.75 & $86 \%$ \\
\hline Bauer et al. $(2014)^{9}$ & $\mathrm{Y}$ & Exp., intraverbal & $\begin{array}{l}\text { Prompting, } \\
\text { Reinforcement }\end{array}$ & Teacher-led & - & - & 10 & 6.3 & $100 \%$ \\
\hline Burgoyne et al. $(2012)^{27}$ & $\mathrm{Y}$ & $\begin{array}{l}\text { Voc., exp. and receptive, } \\
\text { undefined }\end{array}$ & $\begin{array}{l}\text { Manualized } \\
\text { Reading and } \\
\text { Language } \\
\text { Intervention }\end{array}$ & Teacher-led & - & 5 & 40 & 100 & * \\
\hline Camarata et al. $(2006)^{42}$ & $\mathrm{Y}$ & Voc., exp., undefined & Speech Recasting & Learner-directed & - & - & - & 5.5 & $54 \%$ \\
\hline $\begin{array}{l}\text { Chambers \& Rehfeldt } \\
\qquad(2003)^{43}\end{array}$ & $\mathrm{~N}$ & Signs and AAC, exp., mands & $\begin{array}{l}\text { Prompting, } \\
\text { Reinforcement }\end{array}$ & Teacher-led & 10 & 3 & 36 & 19 & $97 \%$ \\
\hline Drash et al. $(1989)^{45}$ & $\mathrm{~N}$ & Voc., exp., echoic & $\begin{array}{l}\text { Prompting, } \\
\text { Reinforcement }\end{array}$ & Teacher-led & - & 12 & 10 & 24 & * \\
\hline $\begin{array}{l}\text { Duker \& Michielsen } \\
\qquad(1983)^{46}\end{array}$ & $\mathrm{~N}$ & Signs, exp., tacts & $\begin{array}{l}\text { Prompting, } \\
\text { Reinforcement }\end{array}$ & Teacher-led & - & 3 & 30 & 17.3 & $72 \%$ \\
\hline Feeley et al. $(2011)^{5}$ & $\mathrm{Y}$ & Voc., exp., echoic and mands & $\begin{array}{l}\text { Prompting, } \\
\text { Reinforcement }\end{array}$ & Teacher-led & 5.5 & 3 & 15 & 8.71 & $76 \%$ \\
\hline Feeley \& Jones $(2008)^{8}$ & $\mathrm{Y}$ & Voc., exp., tacts & $\begin{array}{l}\text { Prompting, } \\
\text { Reinforcement }\end{array}$ & Teacher-led & 10 & 10.5 & - & 8.33 & $76 \%$ \\
\hline Fey et al. $(2006)^{28}$ & $\mathrm{~N}$ & Voc., exp., mands and tacts & Milieu Teaching & Learner-directed & - & 4 & 20 & 80 & $*$ \\
\hline Gutierrez et al. $(2010)^{47}$ & $\mathrm{~N}$ & AAC, exp., mands & Reinforcement & Teacher-led & - & 17 & 5 & 9.5 & $0 \%$ \\
\hline Haring et al. $(1986)^{48}$ & $\mathrm{~N}$ & Voc., exp., intraverbals & $\begin{array}{l}\text { Prompting, } \\
\text { Reinforcement }\end{array}$ & Teacher-led, & 3 & 5 & 10 & 19.5 & $95 \%$ \\
\hline
\end{tabular}




\begin{tabular}{|c|c|c|c|c|}
\hline Heller et al. $(1996)^{49}$ & $\mathrm{~N}$ & AAC, exp., mands & $\begin{array}{l}\text { Prompting, } \\
\text { Reinforcement }\end{array}$ & Teacher-led \\
\hline Hemmeter et al. $(1996)^{50}$ & $\mathrm{~N}$ & Voc., exp., mands & $\begin{array}{l}\text { Prompting, } \\
\text { Reinforcement }\end{array}$ & Learner-directed \\
\hline $\begin{array}{l}\text { Iacono \& Duncum } \\
\qquad(1995)^{51}\end{array}$ & $\mathrm{Y}$ & AAC and voc., exp., tact & $\begin{array}{l}\text { Prompting } \\
\quad \text { Reinforcement }\end{array}$ & Learner-directed \\
\hline Kouri $(1988)^{52}$ & $\mathrm{~N}$ & $\begin{array}{l}\text { Voc. and signs, exp., echoic, } \\
\text { intraverbal, mands and } \\
\text { tacts }\end{array}$ & Prompting & Learner-directed \\
\hline $\begin{array}{l}\text { Kroeger \& Nelson } \\
\qquad(2006)^{53}\end{array}$ & $\mathrm{Y}$ & $\begin{array}{l}\text { Voc., exp., echoic, mands, } \\
\text { tacts, intraverbals }\end{array}$ & $\begin{array}{l}\text { Prompting, } \\
\text { Reinforcement }\end{array}$ & Combination \\
\hline LeBlanc et al. $(2007)^{54}$ & $\mathrm{~N}$ & $\begin{array}{l}\text { Voc., exp., echoic, mands, } \\
\text { tacts, intraverbals }\end{array}$ & NLP & Learner-directed \\
\hline $\begin{array}{l}\text { Mirenda \& Dattilo } \\
\qquad(1987)^{55}\end{array}$ & $\mathrm{~N}$ & AAC, exp., mands & $\begin{array}{l}\text { Prompting, } \\
\text { Reinforcement }\end{array}$ & Teacher-led \\
\hline Poulson $(1988)^{56}$ & $\mathrm{Y}$ & Voc., exp., undefined & Reinforcement & Learner-directed \\
\hline $\begin{array}{l}\text { Remington \& Clarke } \\
\qquad(1993 a)^{57}\end{array}$ & $\mathrm{~N}$ & Signs, exp., tact & $\begin{array}{l}\text { Prompting, } \\
\text { Reinforcement }\end{array}$ & Teacher-led \\
\hline $\begin{array}{l}\text { Remington \& Clarke } \\
\qquad(1993 \mathrm{~b})^{58}\end{array}$ & $\mathrm{~N}$ & Signs, exp., tact & $\begin{array}{l}\text { Prompting, } \\
\text { Reinforcement }\end{array}$ & Teacher-led \\
\hline $\begin{array}{l}\text { Rosales \& Rehfeldt } \\
\qquad(2007)^{59}\end{array}$ & $\mathrm{~N}$ & AAC, exp., mands & Reinforcement & Teacher-led \\
\hline Sepúlveda et al. (2013) ${ }^{29}$ & $\mathrm{Y}$ & Voc., exp., combination & $\begin{array}{l}\text { Morphosyntactic } \\
\text { Grammar } \\
\text { Intervention }\end{array}$ & Peer-led \\
\hline Sigafoos et al. (1989) ${ }^{60}$ & $\mathrm{~N}$ & AAC, exp., mands & $\begin{array}{l}\text { Prompting, } \\
\text { Reinforcement }\end{array}$ & Teacher-led \\
\hline Sigafoos et al. $(2009)^{61}$ & $\mathrm{~N}$ & Voc., exp., mands, tacts & $\begin{array}{l}\text { Prompting, } \\
\text { Reinforcement }\end{array}$ & Teacher-led \\
\hline Tekin-Iftar $(2003)^{62}$ & $\mathrm{~N}$ & Voc., exp., tact & $\begin{array}{l}\text { Prompting, } \\
\text { Reinforcement }\end{array}$ & Peer-led \\
\hline Thompson et al. $(2007)^{63}$ & $\mathrm{~N}$ & Sign, exp., mands & $\begin{array}{l}\text { Prompting, } \\
\quad \text { Reinforcement }\end{array}$ & Teacher-led \\
\hline $\begin{array}{l}\text { Tirapelle \& Cipani } \\
\qquad(1991)^{64}\end{array}$ & $\mathrm{~N}$ & Voc., sign, exp., mands & $\begin{array}{l}\text { Prompting, } \\
\text { Reinforcement }\end{array}$ & Teacher-led \\
\hline Trent et al. $(2005)^{65}$ & $\mathrm{Y}$ & Voc., exp., combination & $\begin{array}{r}\text { Mirroring and } \\
\text { responding }\end{array}$ & Peer-led \\
\hline
\end{tabular}

\begin{tabular}{|c|c|c|c|c|}
\hline 10 & - & - & 3 & $100 \%$ \\
\hline- & 5 & 20 & 11.5 & $88 \%$ \\
\hline- & - & 30 & 6 & $\begin{array}{r}37.50 \\
\%\end{array}$ \\
\hline- & - & 40 & 17 & $65 \%$ \\
\hline- & 7 & 60 & 14 & $80 \%$ \\
\hline 10 & - & 10 & 15 & $100 \%$ \\
\hline- & 39 & 10 & 41 & $95 \%$ \\
\hline- & 2.5 & 12 & - & $91 \%$ \\
\hline 50 & 10 & - & 5 & $75 \%$ \\
\hline 50 & 10 & - & 4.67 & $100 \%$ \\
\hline 18 & 3.5 & 52.5 & 7 & $55 \%$ \\
\hline- & 2 & 30 & 30 & $*$ \\
\hline- & 8 & 5 & - & $100 \%$ \\
\hline 15.5 & 3 & 22.5 & - & $99 \%$ \\
\hline 15 & 7 & - & 17 & $100 \%$ \\
\hline- & 10 & 5 & 100 & $70 \%$ \\
\hline 1 & 7 & - & 30 & $47 \%$ \\
\hline- & - & 5 & 20 & $24 \%$ \\
\hline
\end{tabular}




\begin{tabular}{|c|c|c|c|c|c|c|c|c|c|}
\hline Valentino et al. $(2012)^{66}$ & $\mathrm{~N}$ & Voc., exp., Intraverbals & $\begin{array}{l}\text { Prompting, } \\
\text { Reinforcement }\end{array}$ & Teacher-led & 36 & - & - & 33 & $48 \%$ \\
\hline Warren et al. $(1993)^{67}$ & $\mathrm{~N}$ & $\begin{array}{l}\text { Voc., exp., echoic, } \\
\text { intraverbal, mand, tact }\end{array}$ & Milieu Teaching & Learner-directed & - & 4 & 25 & 62 & $91 \%$ \\
\hline Wright et al. $(2013)^{68}$ & $\mathrm{Y}$ & $\begin{array}{l}\text { Voc., signs, exp., echoic, } \\
\text { intraverbal, mand, tact }\end{array}$ & Milieu Teaching & Learner-directed & - & 2 & 25 & 20 & $77 \%$ \\
\hline Yoder \& Warren $(2002)^{69}$ & $\mathrm{~N}$ & Voc., exp., mands, tacts & Milieu Teaching & Learner-directed & - & 3.5 & 20 & - & $*$ \\
\hline Yoder et al. $(2014)^{17}$ & $\mathrm{~N}$ & Voc., exp., mands, tacts & Milieu Teaching & Learner-directed & - & 3 & 60 & 108 & $*$ \\
\hline
\end{tabular}


Table 4

Percentage non-overlapping and treatment intensity variables data by treatment type.

\begin{tabular}{|c|c|c|c|c|c|c|c|c|c|c|}
\hline Intervention Strategy & $n$ & PND & $\begin{array}{c}\% \\
\text { Reporting } \\
\text { Session } \\
\text { Duration } \\
\end{array}$ & $\begin{array}{c}\text { Session } \\
\text { Duration } \\
\text { (minutes) }\end{array}$ & $\begin{array}{c}\% \\
\text { Reporting } \\
\text { Opportunities } \\
\text { per Session } \\
\end{array}$ & $\begin{array}{l}\text { Opportunities } \\
\text { /Session }\end{array}$ & $\begin{array}{c}\% \\
\text { Reporting } \\
\text { Sessions } \\
\text { per week }\end{array}$ & $\begin{array}{l}\text { Sessions } \\
\text { /week }\end{array}$ & $\begin{array}{c}\% \\
\text { Reporting } \\
\text { Total } \\
\text { Intervention } \\
\text { Duration } \\
\end{array}$ & $\begin{array}{c}\text { Total } \\
\text { Intervention } \\
\text { Duration } \\
\text { (sessions) } \\
\end{array}$ \\
\hline Prompting and & 2 & & $73.07 \%$ & & $48.1 \%$ & & $81.5 \%$ & & $88.0 \%$ & \\
\hline Reinforcement & 7 & & & & & & & & & \\
\hline Mean & & $78.0 \%$ & & 22 & & 18.86 & & 8 & & 20.05 \\
\hline $\mathrm{SD}$ & & $24.6 \%$ & & 16.21 & & 16.28 & & 7.92 & & 19.87 \\
\hline Morphosyntactic & 1 & $* *$ & & 30 & & $*$ & & 2 & & 28 \\
\hline $\begin{array}{l}\text { Manualized Reading and } \\
\text { Language Intervention }\end{array}$ & 1 & $* *$ & & 40 & & $*$ & & 5 & & 100 \\
\hline Speech Recasting & 1 & $54.0 \%$ & & $*$ & & $*$ & & $*$ & & 5.5 \\
\hline Milieu Teaching & 5 & & $100 \%$ & & $0.0 \%$ & & $100 \%$ & & $80.0 \%$ & \\
\hline Mean & 2 & $84.0 \%$ & & 30 & & $*$ & & 3.33 & & 67.5 \\
\hline SD & & $9.9 \%$ & & 16.95 & & $*$ & & 0.84 & & 37.89 \\
\hline Mirroring and Responding & 1 & $24.0 \%$ & & 5 & & $*$ & & 8 & & 20 \\
\hline NLP & 1 & $100 \%$ & & 10 & & 10 & & $*$ & & 15 \\
\hline
\end{tabular}

\footnotetext{
$*$ not reported $* *$ not calculable
} 
Table 5

Intensity characteristics of included studies.

\begin{tabular}{lccccc}
\hline Characteristic & $n$ & $\begin{array}{c}\text { Percent } \\
\text { Reporting }\end{array}$ & Range & Mean & SD \\
\hline Session Duration (minutes) & 28 & $75.68 \%$ & $5-60$ & 23.3 & 16 \\
Opportunities/Session & 14 & $37.84 \%$ & $1-50$ & 18.3 & 15.9 \\
Sessions per week & 29 & $78.38 \%$ & $2-39$ & 6.9 & 7.2 \\
Total Intervention Duration (sessions) & 33 & $89.19 \%$ & $3-108$ & 27.9 & 29 \\
\hline
\end{tabular}

